\title{
Synthesis and electrochemical characteristics of a donor-acceptor porphyrinate rotor mounted on a naphthalocyaninato europium complex
}

\author{
Roman Stefak $^{a}$, N. Ratel-Ramond ${ }^{a}$ and Gwénaël Rapenne* ${ }^{* a, b}$ \\ ${ }^{a}$ CNRS ; CEMES (Centre d'Elaboration de Matériaux et d'Etudes Structurales); BP 94347, 29 rue J. \\ Marvig, F-31055 Toulouse, France. \\ ${ }^{\mathrm{b}}$ Université de Toulouse, UPS, 29 rue J. Marvig, F-31055 Toulouse, France.
}

E-mail: rapenne@cemes.fr

\begin{abstract}
.
A heteroleptic porphyrinate phthalocyaninate donor-acceptor europium double-decker complex was synthesized. The UV-Vis spectral properties and cyclic voltammetry of the compound were investigated and compared to model compounds.
\end{abstract}

Keywords: Europium(III) complexes; Phthalocyanine; Porphyrin; Double-decker complexes ; Donoracceptor complexes

\section{Introduction}

The design and chemical synthesis of artificial molecular machines is currently an important challenge of nanosciences. In the last decade, the continuous improvement of Scanning Tunneling Microscopy (STM) has led to the imaging and the study of physico-chemical properties of various molecules [1]. Such techniques allow the visualization and manipulation of only one molecule and therefore the mechanical properties [2] of a single-molecule deposited on a surface can be investigated. This type of investigations has stimulated the design and synthesis of technomimetic nanomachines [3] that transpose macroscopic machinery at the nanoscale. The main target of such machines is to control their rotative motions for instance in nanogears [4], nanovehicles [5], molecular rotors [6] and motors [7], the latter being a class of rotors capable of producing a potentially useful work. Direct observation of single-molecular rotation with the STM is a very powerful technique to explore the potentiality of rotors as molecular nanomachines and their use as efficient motors.

Since single-molecule experiments require the control of the shape of the molecule deposited, the design and synthesis of rigid molecules able to be covalently attached on surfaces with a minimum number of degrees of freedom is an active field of research [8]. In particular, the movement of a molecule can be efficiently restricted by attaching the molecule to a surface with several legs 
functionalized with thiol or thioether fragments [9], which not only prevents the translation but also gives a very efficient control on the geometry of the whole architecture thanks to the multiple points of attachment. Porphyrin and phthalocyanine based compounds, and in particular their homoleptic and heteroleptic sandwich-type rare-earth complexes (also known as double-decker sandwich complexes) possess remarkable photo and electrochemical properties [10]. Their use as rotors in solution or on surfaces has therefore attracted considerable attention in the last years [11]. Since rotation of the upper ligand around the metal is easily possible, they are promising candidates for controlled functional arrays and molecular mechanical devices because their rotational motions could yield controlled molecular rotors. It has been established that STM can identify the conformation but also can control the lateral arrangement of homoleptic [12] or heteroleptic [13] lanthanide double-decker complexes in two-dimensional arrays, both on metal and on highly oriented pyrolytic graphite (HOPG).

Switching and controlling this rotation are still very challenging, the key issue being the control of the rotation by a physical input at the single molecular scale, but also in the frame of a selfassembled supramolecular network. To achieve this goal, one strategy would be to take advantage of the polarisability of a double-decker architecture induced by the presence of a donor-acceptor rotor (Figure 1). To the best of our knowledge, the preparation and study of such donor-acceptor rotors on surfaces have not been reported so far. The intramolecular rotation of the upper platform of such donoracceptor molecules could be controlled with an electric field induced by the STM tip. For instance, one can expect that a supramolecular network of a donor-acceptor double-decker complex would align unidirectionally as shown on Figure 2, and switch in a synchronized way under the action of the electric field induced by the STM tip, since the application of an electric field will maximize the electrostatic dipole-dipole interactions. One can also imagine tuning the temperature and/or the bias voltage to start or stop the rotation on demand.

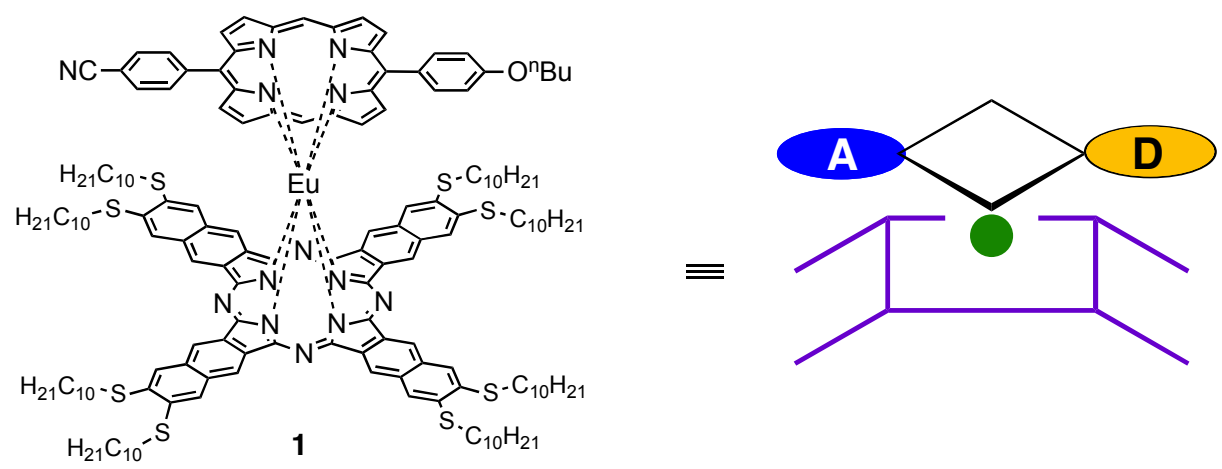

Fig. 1. Chemical and schematic structure of the mixed [(donor-acceptor)phthalocyaninato](porphyrinato) europium double-decker complex $\mathbf{1}$. 

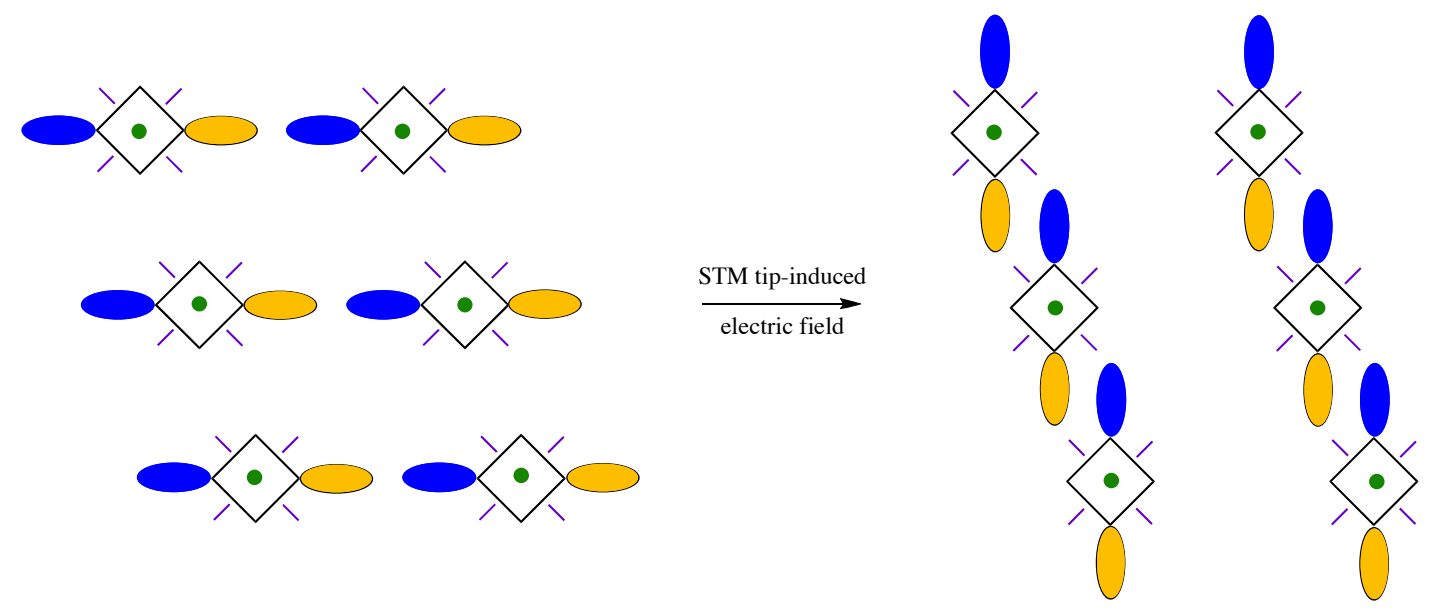

Fig. 2. Expected behavior of a supramolecular network of a donor-acceptor double-decker complex (schematic structure, top view).

In this paper, we describe the preparation of the heteroleptic donor-acceptor-porphyrinate naphthalocyaninate europium double-decker complex presented in Figure 1. The UV-Vis spectral properties and cyclic voltammetry of the compound were investigated and compared to model compounds.

\section{Experimental part}

\subsection{General}

All commercially available chemicals were of reagent grade and were used without further purification. DBU was purchased from Acros, 2,3-dibromo-6,7-dicyanonaphthalene was purchased from TCI, decyl-1-thiol, 2,3-dichloro-5,6-dicyano-1,4-benzoquinone (DDQ), TFA were purchased from Aldrich, 4-cyanobenzaldehyde, $4-{ }^{n}$ butoxybenzaldehyde, $\mathrm{Eu}(\mathrm{acac})_{3} \cdot n \mathrm{H}_{2} \mathrm{O}$ were purchased from Alfa. Dipyrromethane [14] was prepared according to literature procedures. DMSO and octan-1-ol were dried over activated molecular sieves. All reactions were carried out using standard Schlenk techniques under an argon atmosphere. Flash column chromatography was carried out on silica gel 230-400 mesh from SDS.

NMR spectra were recorded on Bruker Avance 300 and Avance 500 spectrometers and full assignments were made using COSY, HMBC and HMQC methods. Chemical shifts are defined with respect to TMS $=0 \mathrm{ppm}$ for ${ }^{1} \mathrm{H}$ and ${ }^{13} \mathrm{C}$ NMR spectra and were measured relative to residual solvent peaks. The following abbreviations have been used to describe the signals: $s$ for singlet; $d$ for doublet; $t$ for triplet; $\mathrm{q}$ for quadruplet; quint for quintuplet; $\mathrm{m}$ for multiplet. The numbering scheme is given in schemes 1 and 2 . 


\subsection{UV-Vis spectroscopic measurements}

UV-Visible-Near Infra-Red spectra were recorded at room temperature on a Varian Cary 5000 spectrometer. EI and DCI $\left(\mathrm{NH}_{3}\right)$ mass spectrometry was performed using a Thermofisher DSQ II, MALDI-TOF and DCI $\left(\mathrm{CH}_{4}\right)$ mass spectrometry were performed using a Waters Maldi Micro MX and a Waters GCT Premier respectively.

\subsection{Electrochemical study}

Cyclic voltammetry was performed with an AUTOLAB PGSTAT 100 potentiostat using a Pt disc (1 $1 \mathrm{~mm}$ diameter) as working electrode and a Pt counter electrode. The reference electrode used was the saturated calomel electrode (SCE).

\subsection{Synthesis}

2,3-Dicyano-6,7-didecylthionaphthalene (4) A mixture of decyl-1-thiol $(0.154 \mathrm{~mL}, 0.743 \mathrm{mmol}$, 2.5 eq.), $\mathrm{K}_{2} \mathrm{CO}_{3}$ (410 mg, $2.97 \mathrm{mmol}, 10$ eq.) and dry DMSO (10 mL) was stirred at room temperature under argon for $30 \mathrm{~min}$. 2,3-Dibromo-6,7-dicyanonaphthalene (100 mg, $0.297 \mathrm{mmol}, 1$ eq.) was added, and the reaction mixture was heated at $80^{\circ} \mathrm{C}$ overnight. The yellow solution was allowed to cool to room temperature and was quenched with brine $(10 \mathrm{~mL})$, extracted with diethyl ether $(2 \times 20 \mathrm{~mL})$, washed with brine $(2 \times 10 \mathrm{~mL})$ and with water $(2 \times 10 \mathrm{~mL})$ and finally dried over magnesium sulfate. The solvent was removed in a rotary evaporator to afford 4 as a yellow solid $(110 \mathrm{mg}, 0.21 \mathrm{mmol}, 71$ $\%$ ). This compound was used without further purification. A pure analytical sample can be obtained by purifiyng the solid by column chromatography $\left(\mathrm{SiO}_{2}\right.$, dichloromethane/hexane 70/30). MS: (EI) $\mathrm{m} / z$ $522.3[\mathrm{M}]^{+}\left(\mathrm{C}_{32} \mathrm{H}_{46} \mathrm{~N}_{2} \mathrm{~S}_{2}\right)$, MS: $\left(\mathrm{DCI} / \mathrm{CH}_{4}\right)$ High Resolution LSI Calculated $[\mathrm{M}+\mathrm{H}]^{+}$: 523.3181 $\left(\mathrm{C}_{32} \mathrm{H}_{47} \mathrm{~N}_{2} \mathrm{~S}_{2}\right)$ Found: $523.3187\left(100 \%[\mathrm{M}+\mathrm{H}]^{+}\right) ;{ }^{1} \mathrm{H}$ NMR: $\left(300 \mathrm{MHz}, \mathrm{CDCl}_{3}\right): \delta 8.15\left(\mathrm{~s}, 2 \mathrm{H}, \mathrm{H}_{\mathrm{a}}\right), 7.57$ $\left(\mathrm{s}, 1 \mathrm{H}, \mathrm{H}_{\mathrm{b}}\right), 3.08\left(\mathrm{t},{ }^{3} \mathrm{~J}=6.9 \mathrm{~Hz}, 4 \mathrm{H}, \mathrm{SCH} \mathrm{H}_{2}\right), 1.79$ (quint, ${ }^{3} \mathrm{~J}=6.9 \mathrm{~Hz}, 4 \mathrm{H}, \mathrm{SCH}_{2} \mathrm{CH}_{2}$ ), 1.52 (quint, ${ }^{3} J=6.9$ $\left.\mathrm{Hz}, 4 \mathrm{H}, \mathrm{SCH}_{2} \mathrm{CH}_{2} \mathrm{CH}_{2}\right), 1.47\left(\mathrm{~m}, 12 \mathrm{H}, \mathrm{S}\left(\mathrm{CH}_{2}\right)_{3}\left(\mathrm{CH}_{2}\right)_{6} \mathrm{CH}_{3}\right) 0.87\left(\mathrm{t},{ }^{3} \mathrm{~J}=6.9 \mathrm{~Hz}, 6 \mathrm{H}, \mathrm{CH}_{2} \mathrm{CH}_{3}\right) ;{ }^{13} \mathrm{C}$ NMR: (125 MHz, $\left.\mathrm{CDCl}_{3}\right)$ : $\delta 142.8\left(\mathrm{C}_{1}\right), 134.1\left(\mathrm{C}_{3}\right), 130.9\left(\mathrm{C}_{2}\right), 123.1\left(\mathrm{C}_{5}\right), 116.1\left(\mathrm{C}_{6}\right), 109.3\left(\mathrm{C}_{4}\right), 33.0$ $\left(\mathrm{SCH}_{2}\right), 31.9,29.6,29.5,29.3,29.2,29.1,28.1,22.7,14.2\left(\mathrm{CH}_{3}\right)$.

5-(4- ${ }^{n}$ Butoxyphenyl)-15-(4-cyanophenyl)porphyrin (2) Dipyrromethane (0.520 g, 3.77 mmol, 2 eq.) was dissolved in dichloromethane $(730 \mathrm{~mL})$. The solution was degassed by repeated vacuum/argon cycles and bubbling with argon over a period of $20 \mathrm{~min}$. To the solution was added 4cyanobenzaldehyde $(0.248 \mathrm{~g}, 1.88 \mathrm{mmol}, 1$ eq. $)$ and $4{ }^{n}{ }^{n}$ butoxybenzaldehyde $(0.327 \mathrm{~mL}, 1.88 \mathrm{mmol}$, 
1 eq.). The flask was protected from light with an aluminium foil and trifluoroacetic acid $(0.183 \mathrm{~mL}$, $2.38 \mathrm{mmol}, 1.3$ eq.) was added dropwise via a syringe. The solution was then stirred at room temperature for 3 h. 2,3-Dichloro-5,6-dicyano-1,4-benzoquinone (DDQ, $1.097 \mathrm{~g}, 4.83 \mathrm{mmol}, 2.6$ eq.) was added and the solution stirred for a further $30 \mathrm{~min}$. The mixture was neutralized with triethylamine $(3.0 \mathrm{~mL})$ and poured directly onto a silica pad $(12 \mathrm{~cm} \times 6 \mathrm{~cm})$ packed in dichloromethane. Fast running porphyrins were collected (including the desired porphyrin) while dark brown DDQ residues were retained by silica gel. The red purple solution was evaporated affording a red purple solid. One first chromatography $\left(\mathrm{SiO}_{2}, 80 \mathrm{~g}\right.$, dichloromethane) was needed to remove all tarry residues and separate an $\mathrm{A}_{2} \mathrm{~B}_{2}$-type fast running porphyrin from the two others $\left(\mathrm{C}_{2} \mathrm{~B}_{2}\right.$ and the desired $\mathrm{AB}_{2} \mathrm{C}$, with $\mathrm{A}=$ ${ }^{n}$ butoxyphenyl, $\mathrm{B}=\mathrm{H}$ and $\mathrm{C}=$ cyanophenyl). A second flash chromatogaphy $\left(\mathrm{SiO}_{2}, 23 \mathrm{~g}\right.$, dichloromethane/hexane $(20: 80 \rightarrow 70: 30))$ was necessary to separate $\mathrm{AB}_{2} \mathrm{C}$ from $\mathrm{C}_{2} \mathrm{~B}_{2} .2$ was obtained as a pure purple glassy solid (166 mg, $0.29 \mathrm{mmol}, 16 \%)$. MS: (DCI/NH $\mathrm{N}_{3} \mathrm{~m} / z 560.2[\mathrm{M}+\mathrm{H}]^{+}$ $\left(\mathrm{C}_{37} \mathrm{H}_{30} \mathrm{~N}_{5} \mathrm{O}\right), 594.2\left[\mathrm{M}+\mathrm{N}_{2} \mathrm{H}_{7}\right]^{+}, 628.1\left[\mathrm{M}+\mathrm{N}_{4} \mathrm{H}_{13}\right]^{+}$; MS: $\left(\mathrm{DCI} / \mathrm{CH}_{4}\right)$ High Resolution LSI Calculated $[\mathrm{M}+\mathrm{H}]^{+}: 560.2450\left(\mathrm{C}_{37} \mathrm{H}_{30} \mathrm{~N}_{5} \mathrm{O}\right)$, Found: $560.2432\left(100 \%[\mathrm{M}+\mathrm{H}]^{+}\right) ;{ }^{1} \mathrm{H}$ NMR: $\left(500 \mathrm{MHz}, \mathrm{CD}_{2} \mathrm{Cl}_{2}\right): \delta$ $10.37\left(\mathrm{~s}, 2 \mathrm{H}, \mathrm{H}_{\mathrm{e}}\right), 9.47\left(\mathrm{~d},{ }^{3} J=4.5 \mathrm{~Hz}, 2 \mathrm{H}, \mathrm{H}_{\mathrm{d}}\right), 9.45\left(\mathrm{~d},{ }^{3} J=4.5 \mathrm{~Hz}, 2 \mathrm{H}, \mathrm{H}_{\mathrm{f}}\right), 9.15\left(\mathrm{~d},{ }^{3} J=4.5 \mathrm{~Hz}, 2 \mathrm{H}\right.$, $\left.\mathrm{H}_{\mathrm{g}}\right), 9.00\left(\mathrm{~d},{ }^{3} J=4.5 \mathrm{~Hz}, 2 \mathrm{H}, \mathrm{H}_{\mathrm{c}}\right), 8.40\left(\mathrm{AA}^{\prime} \mathrm{BB},{ }^{3} J=8.0 \mathrm{~Hz}, 2 \mathrm{H}, \mathrm{H}_{\mathrm{a}}\right), 8.18\left(\mathrm{AA}^{\prime} \mathrm{BB}\right.$ ', ${ }^{3} J=8.5 \mathrm{~Hz}, 2 \mathrm{H}$, $\left.\mathrm{H}_{\mathrm{i}}\right), 8.14\left(\mathrm{AA}^{\prime} \mathrm{BB},{ }^{3} J=8.0 \mathrm{~Hz}, 2 \mathrm{H}, \mathrm{H}_{\mathrm{b}}\right), 7.36\left(\mathrm{AA}^{\prime} \mathrm{BB},{ }^{3} J=8.5 \mathrm{~Hz}, 2 \mathrm{H}, \mathrm{H}_{\mathrm{h}}\right), 4.30\left(\mathrm{t},{ }^{3} J=6.5 \mathrm{~Hz}, 2 \mathrm{H}\right.$, $\left.\mathrm{OCH}_{2}\right), 1.99\left(\mathrm{~m},{ }^{3} \mathrm{~J}=7.5 \mathrm{~Hz}, 2 \mathrm{H}, \mathrm{OCH}_{2} \mathrm{CH}_{2},\right) 1.69\left(\mathrm{~m},{ }^{3} \mathrm{~J}=7.5 \mathrm{~Hz}, 2 \mathrm{H}, \mathrm{OCH}_{2} \mathrm{CH}_{2} \mathrm{CH}_{2},\right) 1.13\left(\mathrm{t},{ }^{3} J=7.5\right.$ $\left.\mathrm{Hz}, 3 \mathrm{H}, \mathrm{CH}_{2} \mathrm{CH}_{3}\right),-3.16$ (s, 2H, NH); ${ }^{13} \mathrm{C} \mathrm{NMR}:\left(125 \mathrm{MHz}, \mathrm{CD}_{2} \mathrm{Cl}_{2}\right)$ : $\delta 159.9\left(\mathrm{C}_{20}\right), 146.9\left(\mathrm{C}_{5}\right), 136.5$ $\left(\mathrm{C}_{18}\right), 135.9\left(\mathrm{C}_{4}\right), 133.7\left(\mathrm{C}_{17}\right), 131.5\left(\mathrm{C}_{3}\right), 120.7\left(\mathrm{C}_{16}\right), 119.7\left(\mathrm{C}_{6}\right), 116.8\left(\mathrm{C}_{1}\right), 113.8\left(\mathrm{C}_{19}\right), 112.4\left(\mathrm{C}_{2}\right)$, $106.1\left(\mathrm{C}_{11}\right), 68.8\left(\mathrm{OCH}_{2}\right), 32.2\left(\mathrm{CH}_{2} \mathrm{CH}_{2}\right), 20.0\left(\mathrm{CH}_{2} \mathrm{CH}_{3}\right), 14.4\left(\mathrm{CH}_{3}\right) ; \mathrm{UV} / \mathrm{Vis}\left(\mathrm{CH}_{2} \mathrm{Cl}_{2} ; \lambda_{\max }(\varepsilon)=264\right.$ (225000), 306 (169200), 359 (58000), 436 (10400); $\lambda_{\max }(\varepsilon)=410$ (403000), 504 (18400), 540 (8500), 577 (6100), 632 (2700); Elemental analysis: calcd for $\mathrm{C}_{37} \mathrm{H}_{29} \mathrm{~N}_{5} \mathrm{O}: \mathrm{C} 79.40, \mathrm{H} \mathrm{5.22,} \mathrm{N} 12.51$, found C 78.81, H 5.33, N 12.01 .

X-ray Crystallographic Study of 2

Purple prismatic crystals suitable for X-ray analysis were obtained by slow evaporation of a solution of the complex in petroleum ether. $\mathrm{C}_{37} \mathrm{H}_{29} \mathrm{~N}_{5} \mathrm{O}: \mathrm{M}_{\mathrm{r}}=1119.3$, triclinic, space group $\mathrm{P} 1, \mathrm{a}(\AA)=10.128$, $\mathrm{b}(\AA)=12.014, \mathrm{c}(\AA)=12.533, \alpha\left(^{\circ}\right)=76.23, \beta\left(^{\circ}\right)=89.67, \gamma\left(^{\circ}\right)=85.83, \mathrm{~V}\left(\AA^{3}\right)=1477, \mathrm{Z}=1, \rho_{\mathrm{calc}}=$ 1.258 g.cm ${ }^{-3}, \mu(\mathrm{MoK})\left(\mathrm{mm}^{-1}\right)=0.078$. Data were collected on a Nonius Kappa CCD diffractometer using MoK $\alpha$ graphite monochromated radiation $(=0.71073 \AA)$ at $293 \mathrm{~K} .7195$ reflections having I > 2(I) were used for structure determination $\left(5.5^{\circ}<2 \theta<32.00^{\circ}\right)$. For all computations the WinGX software package was used [15]. Final results : $R(F)=0.0965, \mathrm{Rw}(\mathrm{F})=0.1819, \mathrm{GoF}=1.128$. 
CCDC 837386 contains the supplementary crystallographic data for this paper. These data can be obtained free of charge from the Cambridge Crystallographic Data Centre via www.ccdc.cam.ac.uk/data_request/cif.

\section{(5-(4- ${ }^{n}$ Butoxyphenyl)-15-(4-cyanophenyl)porphyrinato)(2,3,9,10,16,17,23,24-octakis(1-}

decylthio)napthalocyanato) europium(III) (1) $\mathrm{A}$ mixture of $\mathrm{Eu}(\mathrm{acac})_{3} \cdot n \mathrm{H}_{2} \mathrm{O}(45 \mathrm{mg}, 0.10 \mathrm{mmol}$, 1 eq.) and 5-(4- ${ }^{n}$ butoxyphenyl)-15-(4-cyanophenyl)porphyrin (2) (56 mg, $0.10 \mathrm{mmol}, 1$ eq.) in dry octan-1-ol was refluxed under argon for $12 \mathrm{~h}$. The colour turned from purple to dark brown corresponding to the formation of the europium(III) complex $\mathbf{3}$ which has been used without further purification. 2,3-Dicyano-6,7-didecylthionaphthalene (4) (405 mg, $0.77 \mathrm{mmol}, 7.7$ eq.) and DBU (40 mg, $0.26 \mathrm{mmol}, 2.6$ eq.) were added and the reaction mixture was refluxed for $12 \mathrm{~h}$ to yield a dark green solution. Octan-1-ol was removed by adding water and distillating the azeotropic mixture (octan1-ol/water (10:90), b.p. $99.5{ }^{\circ} \mathrm{C}$, three consecutive distillations with $100 \mathrm{~mL} \mathrm{H}_{2} \mathrm{O}$ each). The residue was then purified by column chromatography $\left(\mathrm{SiO}_{2}\right.$, dichloromethane/hexane $\left.(0: 100 \rightarrow 50: 50)\right)$ to afford a dark green oil (60 mg, $0.021 \mathrm{mmol}, 21 \%)$. MS: (MALDI-TOF/DCTB) $\mathrm{m} / z$ 2801.2 [M] ${ }^{+}$ $\left(\mathrm{C}_{165} \mathrm{H}_{211} \mathrm{~N}_{13} \mathrm{OS}_{8} \mathrm{Eu}\right)$, High Resolution LSI Calculated $[\mathrm{M}+\mathrm{H}]^{+}: 2801.3804\left(\mathrm{C}_{165} \mathrm{H}_{211} \mathrm{~N}_{13} \mathrm{OS}{ }_{8} \mathrm{Eu}\right)$ Found: $2801.3953\left(100 \%[\mathrm{M}+\mathrm{H}]^{+}\right)$; Elemental analysis: calcd for $\mathrm{C}_{165} \mathrm{H}_{210} \mathrm{~N}_{13} \mathrm{OS}{ }_{8} \mathrm{Eu}: \mathrm{C} 70.78, \mathrm{H}$ 7.56, N 6.50, found $\mathrm{C} 70.68, \mathrm{H} 7.44, \mathrm{~N}$ 6.39. UV/Vis $\left(\mathrm{CH}_{2} \mathrm{Cl}_{2} ; \lambda_{\max }(\varepsilon)=230\right.$ (40800), 273 (36300), 324 (37300), 364 (40800), 410 (57600), 546 (8800), 646 (12400), 703 (11800), 974 (2100), 1102 (6600); $\mathrm{CV}\left(\mathrm{CH}_{2} \mathrm{Cl}_{2}\right.$, ${ }^{\mathrm{n}} \mathrm{Bu}_{4} \mathrm{NPF}_{6}$,), E(V/SCE): -1.32 quasi rev, $(1 \mathrm{e}) ;-0.05 \operatorname{rev}(1 \mathrm{e}) ;+0.45 \mathrm{rev}(1 \mathrm{e}) ;+1.04$ quasi rev $(1 \mathrm{e})$.

\section{Results and discussions}

Porphyrin and phthalocyanine ligands are highly delocalized $\pi$ electron systems which exhibit a wide range of intriguing physical properties due to their non innocent nature. When these macrocycles are maintained in close proximity to one another, for instance by the coordination to a metal ion, the two $\pi$ systems interact strongly, yielding new properties. For instance, the neutral porphyrinato naphthalocyanato europium(III) displaying a double-decker sandwich-like structure contains a oneelectron-oxidized $\pi$-radical tetrapyrrole ring as a ligand. It has been established that in such heteroleptic complexes, the electronic hole preferentially resides on the phthalocyanine ring [16]. This result is consistent with higher oxidation potential for monomeric metalloporphyrins compared to metallophthalocyanines. All the neutral complexes of this family can indeed be formulated $\left[\mathrm{M}^{\mathrm{III}}\left(\right.\right.$ porph $\left.^{2-}\right)\left(\right.$ phthalo $\left.\left.^{\circ-}\right)\right]$, phthalo corresponding to phthalocyanines, or in our case to naphthalocyanines (NPc). 
The double-decker europium complex synthesized is shown in Fig. 1 schematically and with its chemical structure. The molecule includes two separate parts : the upper deck, a 5,15-diarylporphyrin, which is designed to act as a rotor and has a permanent electric dipole moment due to the presence of an electron donating and an electron accepting group (butoxy and cyano groups respectively). In order to be able to see a difference in the length-to-width ratio of the rotor by STM, the two other meso positions (positions 10 and 20 on the porphyrin macrocycle) of the molecule are not substituted. The synthesis of the donor-acceptor porphyrin was achieved by reacting freshly prepared dipyrromethane with 2 equivalents of a 1:1 mixture of cyanobenzaldehyde and 4 - $^{n}$ butoxybenzaldehyde (Scheme 1). Oxidation with DDQ provided a mixture of three porphyrins which have been separated by two successive column chromatographies. 2 was obtained pure in $16 \%$ yield and was characterized by ${ }^{1} \mathrm{H}$ and ${ }^{13} \mathrm{C}$ NMR, mass spectrometry, UV-Visible spectroscopy and elemental analysis, all the data being in accordance with the desired structure. The electronic absorption spectrum show typical absorption features of metal-free porphyrin compounds with an intense Soret band at $410 \mathrm{~nm}$ and four weak Q bands at 500, 545, 584 and $638 \mathrm{~nm}$, respectively [17].

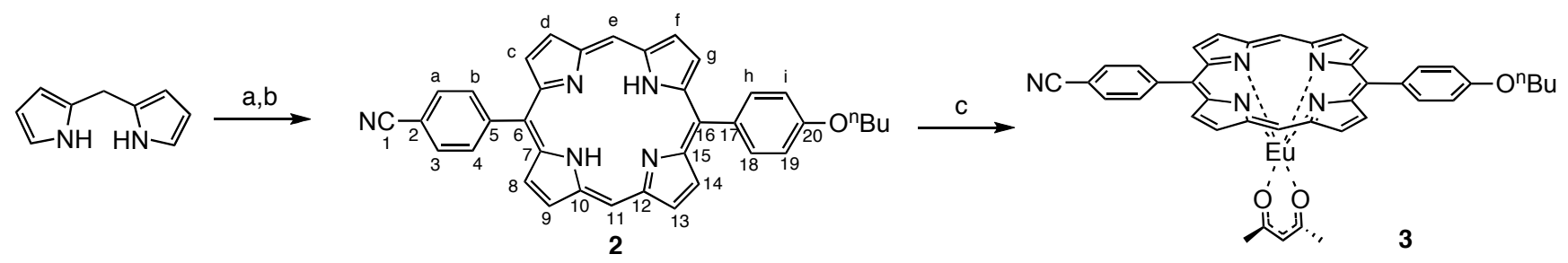

Scheme 1. Synthesis of the donor-acceptor porphyrin and its complexation to yield an europium acetylacetonate complex.

a) 4-" Butoxybenzaldehyde, 4-cyanobenzaldehyde, TFA, $\mathrm{CH}_{2} \mathrm{Cl}_{2}$, $\mathrm{RT}$, argon, 3h; b) DDQ, $30 \mathrm{~min}, 16 \%$;

c) $\mathrm{Eu}(\mathrm{acac})_{3} \cdot \mathrm{nH}_{2} \mathrm{O}$, octanol, reflux, argon, $12 \mathrm{~h}$.

Crystals of 2 suitable for X-Ray diffraction were grown by the slow diffusion of methanol over a dichloromethane solution of the complex. An ORTEP representation is shown in Figure 3. We clearly see the head-to-tail arrangement of molecules in pairs, which is consistent with the donor-acceptor character of the molecule. In agreement with what we can anticipate for this molecule, the electronpoor 4-cyanophenyl fragment lies in close proximity to the electron-rich dipyrrylmethane fragment bearing a butoxyphenyl substituent (these interactions are shown schematically on Figure 3). 


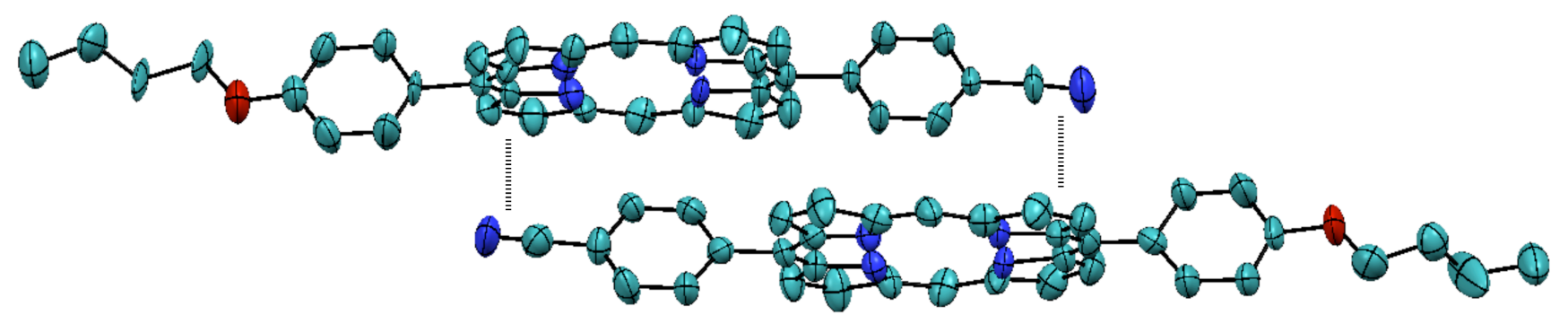

Fig. 3 Thermal ellipsoid diagram of 2 . The ellipsoids are drawn at the 50\% probability level and the hydrogen atoms have been removed for clarity.

The lower deck is a naphthalocyanine macrocycle with eight alkyl sulfide substituents designed to anchor the double decker complex on metallic surfaces through the sulfur atoms. Thioether groups have been chosen since they are known to have a good affinity for metallic surfaces such as copper or gold commonly used in STM experiments [18]. The upper and lower decks are linked via a europium ion, which acts as assembling unit, an ionic joint. Schemes 1 and 2 illustrate the multistep synthesis of the target sandwich complex. The europium double-decker complex has been synthesized following Jiang's efficient one-pot tetramerization of 2,3-dicyano-6,7-didecylthionaphthalene [19].

The free-base porphyrin was treated with 1 equiv. of $\mathrm{Eu}(\mathrm{acac})_{3} \cdot \mathrm{nH}_{2} 0$ in octanol. The conversion was followed through the colour change from purple to dark brown. The UV-Vis. spectrum of the resulting $\mathrm{Eu}^{\text {III }}\left(\mathbf{2}^{2-}\right)\left(\mathrm{acac}^{-}\right)$(3) was similar to the already described tetraphenylporphyrin derivative (TPP)Eu(acac) [20].

Without further purification of the intermediate 3, treatment with 2,3-dicyano-6,7didecylthionaphthalene (4) obtained from the reaction of decylthiol with 2,3-dibromo-6,7-dicyano naphthalene in the presence of potassium carbonate, yielded a dark green solution. Europium(III) acts as a template for the synthesis of the naphthalocyanine ligand. After removal of the solvent, the doubledecker compound 1 (Scheme 2) was further purified by column chromatography, which gave a dark green oil in $21 \%$ yield. 1 has been characterized by high resolution mass spectrometry with detection of the molecular ion bearing the characteristic isotopic profile, UV-Vis. and electrochemistry. Due to the strong paramagnetic character of the molecule, satisfactory NMR spectra could not be obtained even by chemical reduction of the $\pi$-radical tetrapyrrole ring (naphthalocyanine, NPc) using hydrazine in DMSO. 


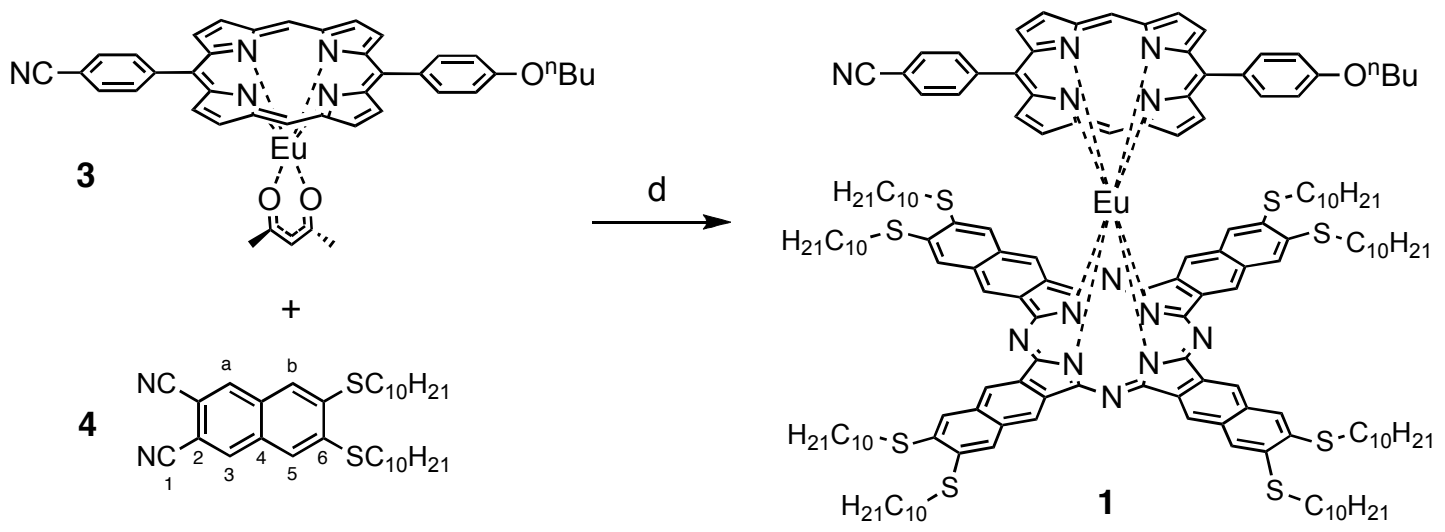

Scheme 2. Synthesis of the double-decker complex 1.d) DBU, octanol, reflux, argon, $21 \%$.

The electronic absorption spectra of the double-decker complex 1 was similar to those reported previously and could be assigned in the same way [16]. The strong absorptions at $365 \mathrm{~nm}$ and $410 \mathrm{~nm}$ can be assigned to the Soret bands of the naphthalocyanine and the porphyrin respectively. Due to symmetry considerations, the number of porphyrin $\mathrm{Q}$ bands is expected to decrease from four to two bands upon metallation, which are found at 650 and $702 \mathrm{~nm}$ in the double-decker molecule. It has been established that the naphthalocyanine Q bands, which are lying in the 500 to $700 \mathrm{~nm}$ region in homoleptic bis-naphthalocyanine double-decker complexes, are absent in the absorption spectrum of the heteroleptic derivatives (TPP)M(NPc). In addition, two bands lying at 538 and $990 \mathrm{~nm}$ (denoted with an asterisk on Figure 4) are characteristic of the electron hole localized on the NPc. The lower energy band appearing in the near-IR region at $1105 \mathrm{~nm}$ is assigned to an intramolecular ligand to ligand charge transfer transition in which the $\mathrm{TPP}^{2-}$ dianionic ligand acts as an electron donor towards the monoanionic $\mathrm{NPc}^{\bullet-}$.

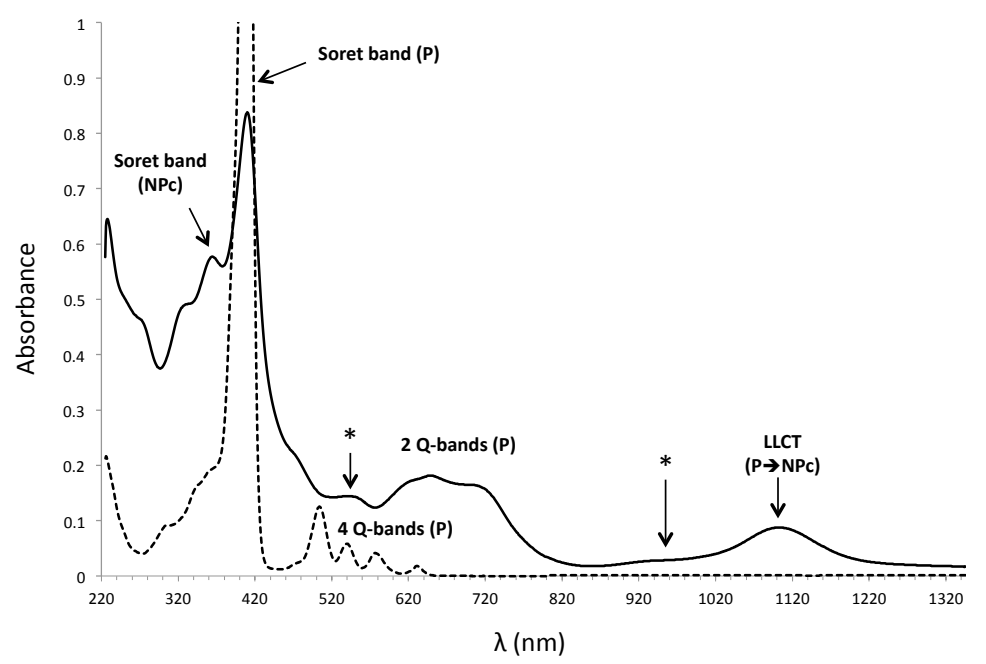

Fig. 4. Electronic absorption of $\mathbf{1}$ (solid line) and $\mathbf{2}$ (dashed line) in dichloromethane. Asterisks denotes typical NPc ${ }^{\bullet-}$ bands. 
The redox behavior of complex 1 was determined by cyclic voltammetry in dichloromethane. The cyclic voltammogram exhibits two reversible and two quasi-reversible one-electron processes (Figure 5). The individual half-wave potentials have been found at 0.45 and $1.04 \mathrm{~V} / \mathrm{SCE}$ in oxidation and -0.05 and $-1.32 \mathrm{~V} / \mathrm{SCE}$ in reduction. These values are comparable to the values measured for $\left[\mathrm{Eu}^{\mathrm{III}}\left(\right.\right.$ porph $\left.^{2-}\right)\left(\right.$ phthalo $\left.\left.^{\bullet-}\right)\right][16]$, the donor and acceptor groups on the porphyrin and the additional fused phenyl rings on the NPc only slightly affect the redox potentials.

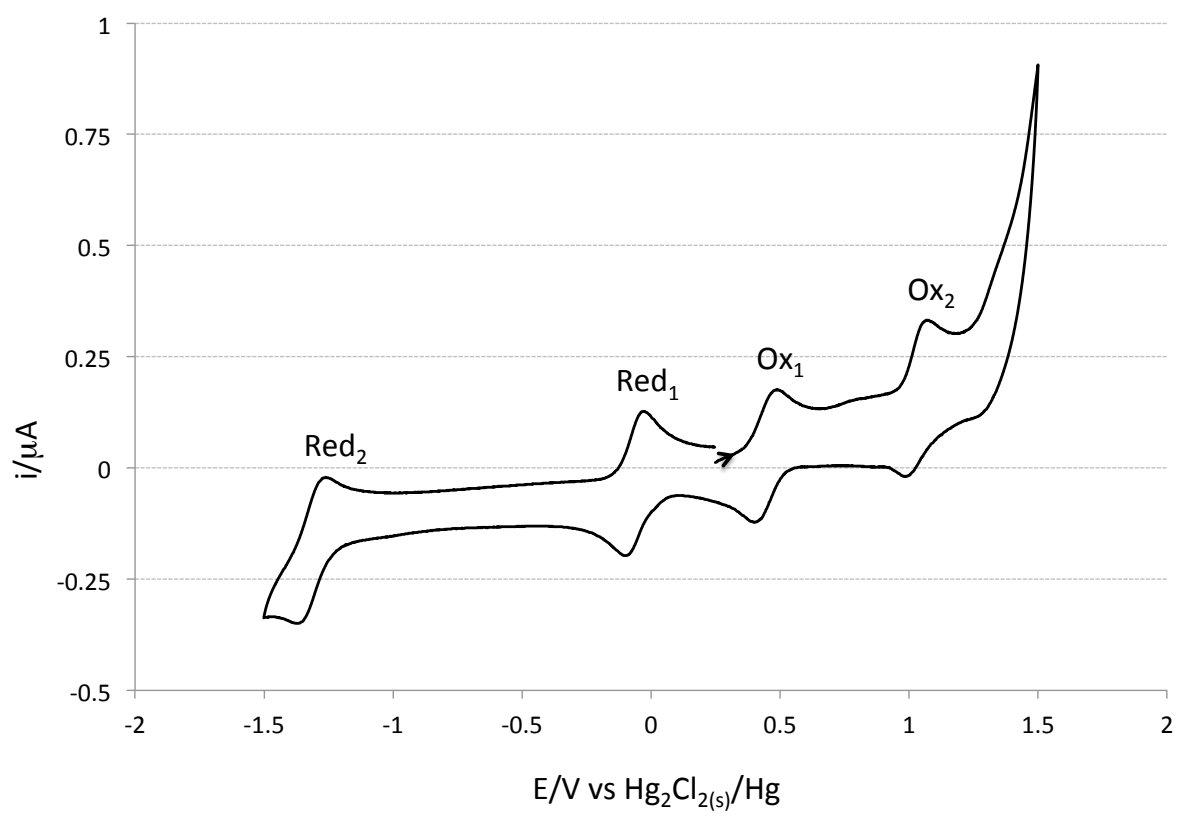

Fig. 5. Cyclic voltammogram of 1 carried out at a scan rate of $100 \mathrm{mV} \cdot \mathrm{s}^{-1}$ in dichloromethane containing $0.1 \mathrm{M} \mathrm{Bu}_{4} \mathrm{NPF}_{6}$ as supporting electrolyte. Potentials were measured vs. SCE using a Pt working electrode. Waves $\operatorname{Red}_{1}$ and $\mathrm{Ox}_{1}$ were reversible, and waves $\operatorname{Red}_{2}$ and $\mathrm{Ox}_{2}$ were quasi-reversible.

\section{Conclusion}

In summary, we have synthesized and characterized a novel polarizable heteroleptic donoracceptor porphyrinate naphthalocyaninate europium double-decker complex as a promising candidate for controlled functional arrays and molecular mechanical devices. Work is currently underway to anchor molecule $\mathbf{1}$ on a metallic surface to study its behavior as a rotor both as single molecule and as self-assembled of a supramolecular network. Using variable temperature STM should grant access to the temperature threshold above which the rotor will rotate freely, as well as to the rotation barrier. We will also explore the possibility to control and/or to switch the rotation with the electric field induced by the STM tip. 


\section{Supplementary material}

Experimental and simulated isotopic patterns for the molecular ions of 1, 2 and $4.1 \mathrm{H}$ and $13 \mathrm{C}$ NMR spectra of 2 and 4.

\section{Acknowledgements}

This work was supported by the CNRS, the University Paul Sabatier (Toulouse) and the ANR P3N AUTOMOL project (ANR $\left.n^{\circ} 09-N A N O-040\right)$. Prof. Jean-Pierre Launay is thanked for his expertise on the measurement of the cyclic voltammogram. Prof. S.W. Hla is also thanked for fruitfull discussions on the design of the molecule. Dr Isabelle M. Dixon is also acknowledged for her corrections and comments on this manuscript.

\section{References}

[1] F. Moresco, Physics Reports 399 (2004) 175 and references therein.

[2] (a) C. Joachim, J.K. Gimzewski, in: Structure and Bonding, vol. 99, Springer, 2001, p. 1; (b) V.L. Popov, Phys. Rev. E 68 (2003) 026608; (c) A. Carella, C. Coudret, G. Guirado, G. Rapenne, G. Vives, J.-P. Launay, Dalton Trans. (2007) 177.

[3] (a) V. Balzani, A. Credi, M. Venturi, Molecular Devices and Machines - A Journey into the Nano World, Wiley-VCH, Weinheim, $2^{\text {nd }}$ ed. 2008 ; (b) G. Rapenne, Org. Biomol. Chem. 3 (2005) 1165.

[4] (a) F. Chiaravalloti, L. Gross, K.H. Rieder, S. Stojkovic, A. Gourdon, C. Joachim, F. Moresco, Nature Mater. 6 (2007) 30; (b) A. Carella, R. Poteau, G. Rapenne, J.-P. Launay, Chem. Eur. J. 14 (2008) 8147 ; (c) C. Manzano, W.-H. Soe, H.S. Wong, F. Ample, A. Gourdon, N. Chandrasekhar, C. Joachim, Nature Mater. 8 (2009) 576.

[5] (a) C. Joachim, F. Moresco, G. Rapenne, G. Meyer, Nanotechnology 13 (2002) 330; (b) G. Rapenne, G. Jimenez-Bueno, Tetrahedron 63 (2007) 7018 ; (c) L. Grill, K.H. Rieder, F. Moresco, G. Rapenne, S. Stojkovic, X. Bouju, C. Joachim, Nature Nanotech. 2 (2007) 95 (d) G. Vives, J.M. Tour, Acc. Chem. Res. 42 (2009) 473.

[6] G. S. Kottas, L. I. Clarke, D. Horinek, J. Michl, Chem Rev. 105 (2005) 1281.

[7] (a) T. R. Kelly, H. D. Silva, R. A. Silva, Nature 401 (1999) 150; (b) N. Koumura, R. W. J. Zijlstra, R. A. van Delden, N, Harada, B. L. Feringa, Nature 401 (1999) 152; (c) D. A. Leigh, J. K. Y. Wong, F. Dehez, F. Zerbetto, Nature 424 (2003) 174; (d); E. R. Kay, D. A. Leigh, F. Zerbetto, Angew. Chem. Int. Ed. 46 (2007) 72 and references therein; (e) G. Vives, A. Gonzalez, J. Jaud, J.-P. Launay, G. Rapenne, Chem. Eur. J. 13 (2007) 5622; (f) G. Vives, H.P. Jacquot de Rouville, A. Carella, J.-P. Launay, G. Rapenne, Chem. Soc. Rev. 38 (2009) 1551.

[8] (a) E. Galoppini, Coord. Chem. Rev. 248 (2004) 1283; (b) Q. Li, C. Jin, P.A. Petukhov, A.V. Rukavishnikov, T.O. Zaikova, A. Phadke, D.H. LaMunyon, M.D. Lee, J.F.W. Keana, J. Org. Chem. 69 (2004) 1010 ; (c) A. Carella, G. Vives, T. Cox, J. Jaud, G. Rapenne, J.-P. Launay, Eur. J. Inorg. Chem. (2006) 980.

[9] (a) Y. Yao, J.M. Tour, J. Org. Chem. 64 (1999) 1968; (b) W. Guo, E. Galoppini, G. Rydja, G. Pardi, Tetrahedron Lett. 41 (2000) 7419; (c) D. Hirayama, K. Takimiya, Y. Aso, T. Otsobu, T. Hasobe, H. Yamada, H. Imahori, S. Fukuzumi, Y. Sakata, J. Am. Chem. Soc. 124 (2002) 532; 
(d) Q. Li, A.V. Rukavishnikov, P.A. Petukhov, T.O. Zaikova, J.F.W. Keana, Org. Lett. 4 (2002) 3631 ; (e) G. Vives, A. Carella, J.-P. Launay, G. Rapenne, Coord. Chem. Rev. 252 (2008) 1451. [10] J. Jiang, D.K.P. Ng, Acc. Chem. Res. 42 (2009) 79.

[11] For rotors based on metal bisporphyrinate double-decker complexes: (a) K. Tashiro, K. Konishi, T. Aida, J. Am. Chem. Soc. 122 (2000) 7921; (b) M. Ikeda, M. Takeuchi, S. Shinkai, F. Tani, Y. Naruta, S. Sakamoto, K. Yamaguchi, Chem. Eur. J. 8 (2002) 5542.

[12] D. Ecija, W. Auwärter, S. Vijayaraghavan, K. Seufert, F. Bischoff, K. Tashiro, J.V. Barth, Angew. Chem. Int. Ed. 50 (2011) 3872 and references therein.

[13] Naphthalocyanine complexes : (a) T. Ye, T. Takami, R. Wang, J. Jiang, P.S. Weiss, J. Am. Chem. Soc. 128 (2006) 10984; (b) T. Takami, T. Ye, B.K. Pathem, D.P. Arnold, K. Sugiura, Y. Bian, J. Jiang, P.S. Weiss, J. Am. Chem. Soc. 132 (2010) 16460; (c) T. Takami, T. Ye, D.P. Arnold, K. Sugiura, R. Wang, J. Jiang, P.S. Weiss, J. Phys. Chem. C 111 (2007) 2077; Phthalocyanine complexes : (a) K. Miyake, M. Fukuta, M. Asakawa, Y. Hori, T. Ikeda, T. Shimizu, J. Am. Chem. Soc. 131 (2009) 17808; (b) X. Zhang, Q. Wang, L. Vu, W. Lv, J. Lu, Y. Bian, J. Jiang, P.S. Weiss, J. Phys. Chem. B 114 (2010) 1233.

[14] M. Balaz, H.A. Collins, E. Dahlstedt, H.L. Anderson, Org. Biomol. Chem. 7 (2009) 874.

[15] L.J. Farrugia (1999), J. Appl. Cryst. 32, 837-838

[16] (a) D. Chabach, M. Tahiri, A. De Cian, J. Fischer, R. Weiss, M. El Malouli Bibout, J. Am. Chem. Soc. 117 (1995) 8548; (b) Y. Bian, J. Jiang, Y. Tao, M.T.M. Choi, R. Li, A.C.H. Ng, P. Zhu, N. Pan, X. Sun, D.P. Arnold, Z.-Y. Zhou, H.-W. Li, T.C.W. Mak, D.K.P. Ng, J. Am. Chem. Soc. 125 (2003) 1225.

[17] H. L. Anderson, Chem. Commun. (1999) 2323.

[18] (a) J.M. Tour, L. Jones, D.L. Pearson, J.J.S. Lamba, T.P. Burgin, G.M. Whitesides, D.L. Allara, A.N. Parikh, S. Atre, J. Am. Chem. Soc. 117 (1995) 9529; (b) D.T. Gryko, C. Clausen, J.S. Lindsey, J. Org. Chem. 64 (1999) 8635.

[19] (a) T. Nyokong, F. Furuya, N. Kobayashi, D. Du, W. Liu, J. Jiang, Inorg. Chem. 39 (2000) 128 ; (b) R. Wang, Y. Li, R. Li, D.Y.Y. Cheng, P. Zhu, D.K.P. Ng, M. Bao, X. Cui, N. Kobayashi, J. Jiang, Inorg. Chem. 44 (2005) 2114 ; (c) J. Jiang, R.L.C. Lau, T.W.D. Chan, T.C.W. Mak, D.K.P. Ng, Inorg. Chim. Acta 255 (1997) 59; (d) V.E. Pushkarev, A.Y. Tolbin, N.E. Borisova, S.A. Trashin, L.G. Tomilova, Eur. J. Inorg. Chem. (2010) 5254.

[20] C.-P. Wong, Inorg. Synth. 22 (1983) 156. 